\title{
Effect of magnetized ethanol-gasoline blends on vibration and sound emissions of a single cylinder Sl engine
}

Hosna Faraji

llam University

Kobra Heidarbeigi ( $\nabla$ kobra.heidarbeigi@gmail.com )

Ilam University https://orcid.org/0000-0002-6294-9794

Sadegh Samadi

Ilam University

Original Article

Keywords: Engine, Ethanol, Magnetic field, Sound pollution, Vibration

Posted Date: May 28th, 2020

DOI: https://doi.org/10.21203/rs.3.rs-28891/v2

License: (c) (1) This work is licensed under a Creative Commons Attribution 4.0 International License.

Read Full License 
The authors have withdrawn this preprint from Research Square 